\title{
Knowledge, Attitudes and Practice Behaviour of Midwives Concerning Periodontal Health of Pregnant Patients
}

\author{
Jennifer Gia-linh Nguyen ${ }^{1} * \mathbb{E}$, Shanika Nanayakkara ${ }^{2}$ and Alexander C. L. Holden ${ }^{2}$ (D) \\ 1 Faculty of Dentistry, University of British Columbia, Vancouver, BC V6T 1Z3, Canada \\ 2 Faculty of Medicine and Health, University of Sydney School of Dentistry, Westmead, NSW 2145, Australia; \\ shanika.nanayakkara@sydney.edu.au (S.N.); alexander.holden@sydney.edu.au (A.C.L.H.) \\ * Correspondence: jgn.jennifer@gmail.com
}

Received: 4 March 2020; Accepted: 23 March 2020; Published: 27 March 2020

check for updates

\begin{abstract}
Maternal gum disease is associated with adverse pregnancy outcomes such as preterm birth and low birthweight. This study aims to evaluate the knowledge, attitudes and practice behaviour of Australian midwives regarding the periodontal health of pregnant women to inform interprofessional antenatal care. This was an observational, cross-sectional study. We circulated an online questionnaire to Australian midwives from August 2018 to February 2019. Key outcome variables were knowledge, attitudes, and practice behaviours related to oral health. Key predictor variables were years of practice, practice location, and dental history. We summarized responses with frequency tables and assigned tallied scores for analysis using non-parametric statistical tests. 100 responses were analysed, including from rural $(n=23)$ and urban $(n=77)$ midwives. Eighty percent of midwives agreed that maternal dental care can positively affect pregnancy outcomes. Fluoridated toothpaste use $(19.1 \%)$ was incorrectly answered to prevent gum disease more often than psychological stress control (7.9\%), a correct answer. Rural midwives demonstrated a significantly higher knowledge score $(p=0.001)$ and significantly more positive practice behaviours towards oral health $(p=0.014)$ than urban midwives. Australian midwives have positive attitudes towards antenatal oral health but misunderstand gum disease aetiology and prevention. This study highlights areas to improve interprofessional education for optimal oral health and pregnancy outcomes.
\end{abstract}

Keywords: midwifery; oral health; pregnancy; periodontal disease; adverse pregnancy outcomes; prenatal care; maternal health; interprofessional education; provider practices; women's health

\section{Introduction}

Oral infections, especially periodontal disease, are associated with an increased level of systemic inflammation and may contribute to poorer outcomes for systemic diseases such as diabetes, respiratory disease, cardiovascular disease, and osteoporosis [1-6]. Periodontal disease is a chronic, inflammatory bacterial infection of the tissues surrounding the teeth, which progresses from gingivitis-initial inflammation of the gums [4,7]. Women are at an increased risk of developing oral diseases such as periodontal disease and dental caries during pregnancy, due to elevated concentrations of oestrogen and progesterone, increased systemic levels of inflammatory cytokines, nausea and gastroesophageal reflux disease, and increased incidence of snacking [8-12]. Up to 75\% of women develop gingivitis during pregnancy, while $20 \%-50 \%$ of women have periodontal disease which worsens during pregnancy $[13,14]$. Periodontal disease during pregnancy is correlated with adverse pregnancy outcomes such as preterm delivery, low birthweight, and pre-eclampsia [11,15-19]. Periodontal disease is a direct consequence of untreated gingivitis, and is treatable and preventable with early intervention, oral health education 
and screening $[7,20,21]$. In this light, monitoring and maintaining periodontal health in pregnant patients presents an opportunity for interprofessional collaboration in health care to improve patient outcomes [20,22-24].

Previous research has investigated the attitudes and practice behaviours of health professionals, including obstetricians, gynaecologists, nurses, midwives and dentists, towards oral health during pregnancy. Although obstetricians and gynaecologists were aware of the association between periodontal disease and adverse pregnancy outcomes, their attitudes and practice behaviour regarding antenatal oral health did not match accordingly $[25,26]$. Most obstetricians and gynaecologists accepted that there is minimal discussion of oral health during care of pregnant females, and they identified limited time for consultations as a major reason for this approach $[14,27,28]$. Other studies reported that, although most midwives and nurses referred pregnant patients for dental care, many midwives and nurses were not aware of appropriate referral pathways to a dentist and felt inadequately trained to provide oral health information to pregnant patients [29-31]. Most health professionals believed it is mainly the dentist's role to provide oral health information to pregnant patients $[14,30,32,33]$.

It has been reported that, although dentists are aware of the association between poor oral health and advanced pregnancy outcomes, pregnant women are often not referred to the dentist for routine dental care, and misconceptions also persist regarding the safety of dental care during pregnancy $[26,34,35]$. Furthermore, while finances are another barrier for pregnant women to seeking routine dental care, most of them are also unaware of the importance of oral health during pregnancy and assumed that poor oral health was a normal change during pregnancy [29,36-39]. Overall, this paints a picture of unclear knowledge amongst health care professionals regarding antenatal oral care management and presents areas to improve interprofessional coordination of care and referral for antenatal oral health. Improved inter-disciplinary communication and frameworks for collaboration can lead to better patient outcomes in antenatal oral health [40-42].

Midwives, as antenatal and post-natal care providers, tend to care for pregnant patients over a longer period of time than obstetricians, providing pregnant patients with continuity of care, health education, and opportunities for interprofessional collaboration for improved patient outcomes [43-45]. In this light, midwives can play an important role in providing antenatal oral health screening and education, as well as dental referrals [40,46]. Furthermore, recent surveys have also reported that Australian women are positive towards receiving oral health advice from midwives during pregnancy $[38,47]$.

International guidelines in the United States, the UK and Europe encourage antenatal oral health screening, education and referral for dental care starting from early pregnancy, as there is an association between antenatal periodontal disease and adverse pregnancy outcomes [23,48-50]. Australian national antenatal care guidelines were updated in 2012 to promote oral health screening for all pregnant patients, as oral health is important for maternal health, and dental treatment can be provided safely during pregnancy [51,52]. Despite guideline changes to include oral health in midwifery training, Australian midwifery programs contain minimal formal content regarding oral health [40,53-55]. Previous research found that midwives believe oral health is important during pregnancy but have inadequate knowledge regarding antenatal oral health care and education [30,31].

The purpose of this study is to evaluate the current knowledge, attitudes, and practice behaviours of midwives in Australia regarding the periodontal health of pregnant women to inform and identify areas to improve antenatal care.

\section{Materials and Methods}

All subjects gave their informed consent for inclusion before they participated in the study. The study was conducted in accordance with the Declaration of Helsinki, and ethical clearance for this study was granted by the University of Sydney Human Research Ethics Committee (Project No. 2017/659). 
A three-part questionnaire with 31 items was developed based on an amalgamation of previously published, validated questionnaires [14,28,30] (Appendix A). The questionnaire was then sent to an expert panel, consisting of a periodontist, an oral health therapist, and a midwife currently practicing in Australia, for survey pretesting and feedback prior to circulation to participants [56]. The first part of the questionnaire was comprised of eight multiple-choice questions regarding knowledge of clinical signs and pathogenesis of periodontal disease, as well as its link to pregnancy. The second part was comprised of twelve questions in total-eight Likert-scale questions on participants' attitudes and opinions towards periodontal health, and four close-ended questions on participants' practice behaviour related to oral health during pregnancy. The third section, with ten close-ended questions and one Likert-style question, evaluated participants' socio-demographics and oral health status and care. Further questionnaire modifications were made based on the expert panel's suggestions, to highlight the role of dental plaque debridement in ameliorating periodontal disease progression, as opposed to the role of dental plaque control in preventing dental caries. This is because the difference between dental caries and periodontal disease is often misunderstood by the general public.

Question phrasing and structure were revised in this study to minimize response bias and optimize response rate, based on the survey's online method of distribution [56-58]. Questions were structured to only cover one idea or topic per item to provide clarity of interpretation and more accurate response data. Survey questions were also worded to avoid using double negatives, avoid biased phrasing that could encourage participants to give certain answers, and avoid questions about hypothetical scenarios or future intentions, as these question formats tend to provide unreliable data about respondent behaviour [57,58]. Likert-style questions with a five-point scale were used to give a more accurate representation of both participants' general attitude and the intensity of their opinions on statements in the survey [57] (p. 770). A close-ended response format was used to provide more reliable uniformity of responses for analysis and ease of administration for an online survey format. Since the study questionnaire covered sensitive topics such as attitudes and clinical practice behaviours, participants were more likely to give accurate and truthful answers with a close-ended format $[57,58]$. This study used an online self-completion method of distribution for the survey to reduce response bias from having an interviewer present, while allowing participants to answer sensitive questions more honestly [57] (p. 775).

Facebook groups were used to sample participants due to their cost effectiveness, wide audience reach, and increased timeliness in gathering responses through this medium [56]. Using an online method to gather participants also encourages accessibility for midwives located across Australia, including in rural areas. The alternative method of contacting midwives via hospital lists and private practices would have involved greater administrative complexity via multiple interstate Australian bodies to gain ethics approval, more time, and a projected smaller participant reach. Study participants were recruited from six Facebook groups for professional midwives in Australia, entitled "Midwifery Group Practice in Australia", "Registered Nurses \& Midwives in Australia", "Call the Student Midwife (Australia)", "Midwifery Contracts in Australia", "Midwifery Students and Novice Midwives of Melbourne, Australia", and "South Australian Midwifery Students". These Facebook groups were selected for the study as they were tailored towards midwives in Australia, had the largest group membership, and were active groups. Participants could circulate the questionnaire to their colleagues to participate in the study, even if the colleague was not a member of one of the listed midwifery Facebook groups. The eligibility criteria for participation were either being a midwife currently practicing in Australia or being a current midwifery student at an Australian institution. The questionnaire was circulated by posting a link to the online survey in the midwifery Facebook group. Members of the Facebook groups were reminded one month and two months after initial circulation of the questionnaire to participate in the study. Study data was collected from August 2018 to February 2019. Questionnaires with answers to all the questions were included in the analysis.

Questionnaire data was collected on REDCap, an encrypted, secure server hosted by the University of Sydney, and participant responses were de-identified through this process [59,60]. Geographical 
data was mapped using QGIS. Key outcome variables are knowledge, attitudes, and practice behaviour related to oral health. Key predictor variables are practice setting (urban versus rural), years of professional experience, and personal dental history.

Statistical analyses were performed using IBM SPSS Statistics (version 23, IBM SPSS Inc., Chicago, IL). Frequency tables were used to summarize the responses. Questionnaire responses regarding knowledge (Part 1) and attitudes and practice behaviours (Part 2) were assigned tallied scores for further analysis using non-parametric statistical tests. A higher knowledge score indicated better knowledge and a higher attitude score indicated more positive attitudes toward oral health. For all statistical analysis, the significance level was set at $\mathrm{p} \leq 0.05$.

\section{Results}

One hundred and four complete questionnaires were collected, and one hundred questionnaires were included for analysis. Four questionnaires were eliminated because the participants were not currently working midwives in Australia. The mean age of participants was 37.5 years old \pm 12.34 $($ minimum $=20$, maximum $=62)$. The median number of years of professional experience was less than 10 years (Table 1). Geographical distribution of study participants across Australia was diverse, with respondents from northern, eastern, western, and southern regions of Australia, including Tasmania (Figure A1). More participants were from areas with higher population concentrations, such as Sydney and Melbourne. In terms of practice setting, most participants (77.0\%) practiced in an urban setting, while $23.0 \%$ participants practiced rurally. The majority of participants $(85.0 \%)$ practiced in a hospital setting, while some (13.0\%) practiced at a mixture of hospital and private practice. In terms of dental history, most participants $(87.0 \%)$ visited the dentist between every 6-18 months, and most participants rated their oral health as excellent $(22.0 \%)$ or good $(58.0 \%)$. Only $23.0 \%$ of participants had been diagnosed with periodontal disease in the past, and $22.0 \%$ had received treatment for periodontal disease.

Table 1. Demographic characteristics and dental history of participants.

\begin{tabular}{cccc}
\hline & & $\%$ & $\mathbf{n}$ \\
\hline \multirow{2}{*}{ Gender } & Female & $100.0 \%$ & 100 \\
& Male & $0.0 \%$ & 0 \\
& Other & $0.0 \%$ & 0 \\
\hline \multirow{2}{*}{ Number of years in midwifery practice } & Current midwifery student & $32.0 \%$ & 32 \\
& Less than 10 years & $44.0 \%$ & 44 \\
& $10-20$ years & $11.0 \%$ & 11 \\
& $21-30$ years & $10.0 \%$ & 10 \\
Current occupation & 31-40 years & $6.0 \%$ & 6 \\
& $40+$ years & $0.0 \%$ & 0 \\
\hline \multirow{2}{*}{ Midwifery practice location } & Currently practicing midwife & $68.0 \%$ & 68 \\
& in Australia & $32.0 \%$ & 32 \\
& Current midwifery student & $0.0 \%$ & 0 \\
& Unemployed & $0.0 \%$ & 0 \\
\hline \multirow{2}{*}{ Midwifery practice setting } & Retired midwife & $77.0 \%$ & 77 \\
& Urban & $23.0 \%$ & 23 \\
\hline & Rural & $85.0 \%$ & 85 \\
& Hospital and private practice & $13.0 \%$ & 13 \\
& Private practice & $2.0 \%$ & 2 \\
\hline
\end{tabular}


Table 1. Cont.

\begin{tabular}{cccc}
\hline & & $\mathbf{\%}$ & $\mathbf{n}$ \\
\hline & Excellent & $22.0 \%$ & 22 \\
How would you rate your oral health? & Good & $58.0 \%$ & 58 \\
& Neutral & $14.0 \%$ & 14 \\
& Poor & $6.0 \%$ & 6 \\
& Very poor & $0.0 \%$ & 0 \\
\hline How often do you visit the dentist? & Every 6 months & $33.0 \%$ & 33 \\
& Every 12 months & $33.0 \%$ & 33 \\
& Every 12-18 months & $21.0 \%$ & 21 \\
& Only if in pain & $12.0 \%$ & 12 \\
Have you ever been diagnosed with & Never & $1.0 \%$ & 1 \\
periodontal disease? & Yes & $23.0 \%$ & 23 \\
Have you ever been diagnosed and & No & $77.0 \%$ & 77 \\
received treatment for periodontal disease? & Yes & $22.0 \%$ & 22 \\
\hline
\end{tabular}

\subsection{Knowledge and Attitudes Towards Periodontal Disease}

Sixty-three percent of participants correctly understood that periodontal disease is an inflammatory condition involving bacterial infection. However, nearly a third of participants (31.8\%) incorrectly believed that periodontal disease is a degenerative process. Participants correctly listed gingival bleeding $(28.9 \%)$, tooth mobility $(21.6 \%)$ and tooth loss $(21.0 \%)$ as clinical signs of periodontal disease, but caries $(16.0 \%)$ was often also mistaken as a sign of periodontal disease. In terms of aetiological factors for gum disease, poor oral hygiene $(23.5 \%)$ and smoking $(20.0 \% ; 18.2 \%)$ were often correctly identified as aetiological factors associated with initiation and progression of gum disease. However, tooth decay $(10.0 \%)$ was often also incorrectly chosen as an aetiological factor, more often than genetics $(9.0 \%)$ and pregnancy $(8.6 \%)$.

The majority of participants $(83.0 \%)$ believed that periodontal disease influences pregnancy outcomes. Furthermore, most participants (98.0\%) agreed that periodontal diseases can be prevented or arrested during pregnancy. In terms of prevention of periodontal disease, the correct options of effective toothbrushing technique (25.4\%), interdental brush use $(25.1 \%)$, and smoking cessation $(22.5 \%)$ were chosen, as well as the incorrect answer of fluoridated toothpaste use (19.1\%), with similar frequency (Table 2). Interestingly, the correct answer of psychological stress control was chosen only $7.9 \%$ of the time as part of periodontal disease prevention.

Table 2. Midwives' knowledge of periodontal disease ${ }^{1}$.

\begin{tabular}{cccc}
\hline Survey Question & Respondent Answer & $\%$ & $\mathbf{n}$ \\
\hline & Inflammation and bacterial infection & $63.0 \%$ & 97 \\
Definition of periodontal disease & Degenerative process & $31.8 \%$ & 49 \\
$(\mathrm{~N}=154)$ & Auto-immune disorder & $2.0 \%$ & 3 \\
& Osteoporosis & $2.0 \%$ & 3 \\
& Metastatic process & $1.3 \%$ & 2 \\
\hline Clinical signs associated with & Gingival bleeding & $28.9 \%$ & 99 \\
periodontal disease & Tooth mobility & $21.6 \%$ & 74 \\
$(\mathrm{~N}=343)$ & Tooth loss & $21.0 \%$ & 72 \\
& Caries & $16.0 \%$ & 55 \\
& Alveolar bone destruction & $12.5 \%$ & 43 \\
\hline
\end{tabular}


Table 2. Cont.

\begin{tabular}{|c|c|c|c|}
\hline Survey Question & Respondent Answer & $\%$ & $\mathbf{n}$ \\
\hline \multirow{7}{*}{$\begin{array}{l}\text { Risk factors for gum } \\
\text { disease initiation } \\
\quad(\mathrm{N}=409)\end{array}$} & Poor oral hygiene & $23.5 \%$ & 96 \\
\hline & Smoking & $20.0 \%$ & 82 \\
\hline & Excessive sugar consumption & $14.7 \%$ & 60 \\
\hline & Tooth decay & $10.0 \%$ & 41 \\
\hline & Dental plaque & $14.2 \%$ & 58 \\
\hline & Genetics & $9.0 \%$ & 37 \\
\hline & Pregnancy & $8.6 \%$ & 35 \\
\hline \multirow{7}{*}{$\begin{array}{l}\text { Risk factors for gum } \\
\text { disease progression } \\
\qquad(\mathrm{N}=396)\end{array}$} & Poor oral hygiene & $23.5 \%$ & 93 \\
\hline & Smoking & $18.2 \%$ & 72 \\
\hline & Excessive sugar consumption & $16.4 \%$ & 65 \\
\hline & Tooth decay & $11.6 \%$ & 46 \\
\hline & Dental plaque & $15.9 \%$ & 63 \\
\hline & Genetics & $3.0 \%$ & 12 \\
\hline & Pregnancy & $11.4 \%$ & 45 \\
\hline \multirow{4}{*}{$\begin{array}{l}\text { Oral signs often related } \\
\text { to pregnancy } \\
(\mathrm{N}=162)\end{array}$} & Gingival bleeding & $61.1 \%$ & 99 \\
\hline & Gingival overgrowth & $20.4 \%$ & 33 \\
\hline & Caries & $9.3 \%$ & 15 \\
\hline & Tooth loss & $9.3 \%$ & 15 \\
\hline \multirow{6}{*}{$\begin{array}{l}\text { Do periodontal diseases influence } \\
\text { pregnancy outcomes? } \\
\qquad(\mathrm{N}=192)\end{array}$} & Yes - Increased incidence of preterm birth & $34.9 \%$ & 67 \\
\hline & $\begin{array}{c}\text { Yes - Increased incidence of } \\
\text { low-weight newborn }\end{array}$ & $20.3 \%$ & 39 \\
\hline & $\begin{array}{l}\text { Yes - Increased incidence of } \\
\text { spontaneous abortion }\end{array}$ & $17.7 \%$ & 34 \\
\hline & $\begin{array}{c}\text { Yes - Increased incidence of low } \\
\text { genital-tract infection }\end{array}$ & $10.4 \%$ & 20 \\
\hline & Yes - increased incidence of pre-eclampsia & $7.8 \%$ & 15 \\
\hline & No & $8.9 \%$ & 17 \\
\hline \multirow{2}{*}{$\begin{array}{l}\text { Are periodontal diseases } \\
\text { preventable during pregnancy? } \\
\qquad(\mathrm{N}=100)\end{array}$} & $\begin{array}{c}\text { Yes - They can be prevented or arrested } \\
\text { during pregnancy }\end{array}$ & $98.0 \%$ & 98 \\
\hline & $\begin{array}{c}\text { No - They're an expected side effect } \\
\text { during pregnancy }\end{array}$ & $2.0 \%$ & 2 \\
\hline \multirow{5}{*}{$\begin{array}{l}\text { Periodontal diseases can be } \\
\text { prevented by: } \\
(\mathrm{N}=382)\end{array}$} & Effective toothbrushing technique & $25.4 \%$ & 97 \\
\hline & Using dental floss or interdental brushes & $25.1 \%$ & 96 \\
\hline & Smoking cessation & $22.5 \%$ & 86 \\
\hline & Using fluoridated toothpaste & $19.1 \%$ & 73 \\
\hline & Control of psychological stress & $7.9 \%$ & 30 \\
\hline
\end{tabular}

\footnotetext{
${ }^{1}$ Respondents were allowed to choose more than one answer for these questions, thus the number of responses per
} question varied depending on the total number of responses chosen per question.

Most respondents (81.0\%) agreed that periodontal disease can have an adverse effect on pregnancy outcomes, and $80.0 \%$ of participants agreed that treatment of periodontal disease during pregnancy positively affects pregnancy outcomes (Table 3).

In terms of oral health assessment during a midwifery visit, most respondents (69.0\%) believed that asking pregnant patients about their oral health is within the routine practices of a midwife. Sixty percent of participants routinely ask questions related to oral health during consultation with pregnant patients. Most participants (79.0\%) also provide oral-health-related information during a consultation with pregnant patients routinely or if the patient is considered at risk. However, only $16.0 \%$ of participants felt that they were up to date on the topic of oral health and pregnancy. Nearly half of the participants $(49.0 \%)$ routinely refer patients to their dentist for check-ups. Most participants $(81.0 \%)$ believed that conducting an examination of the oral cavity during pregnancy is outside the routine practices of a midwife. 
Regarding the statement "There is insufficient time to address oral health during a care visit with a midwife", $42.0 \%$ of participants agreed, while $40.0 \%$ disagreed.

Table 3. Midwives' attitudes and practice behaviours regarding maternal periodontal disease.

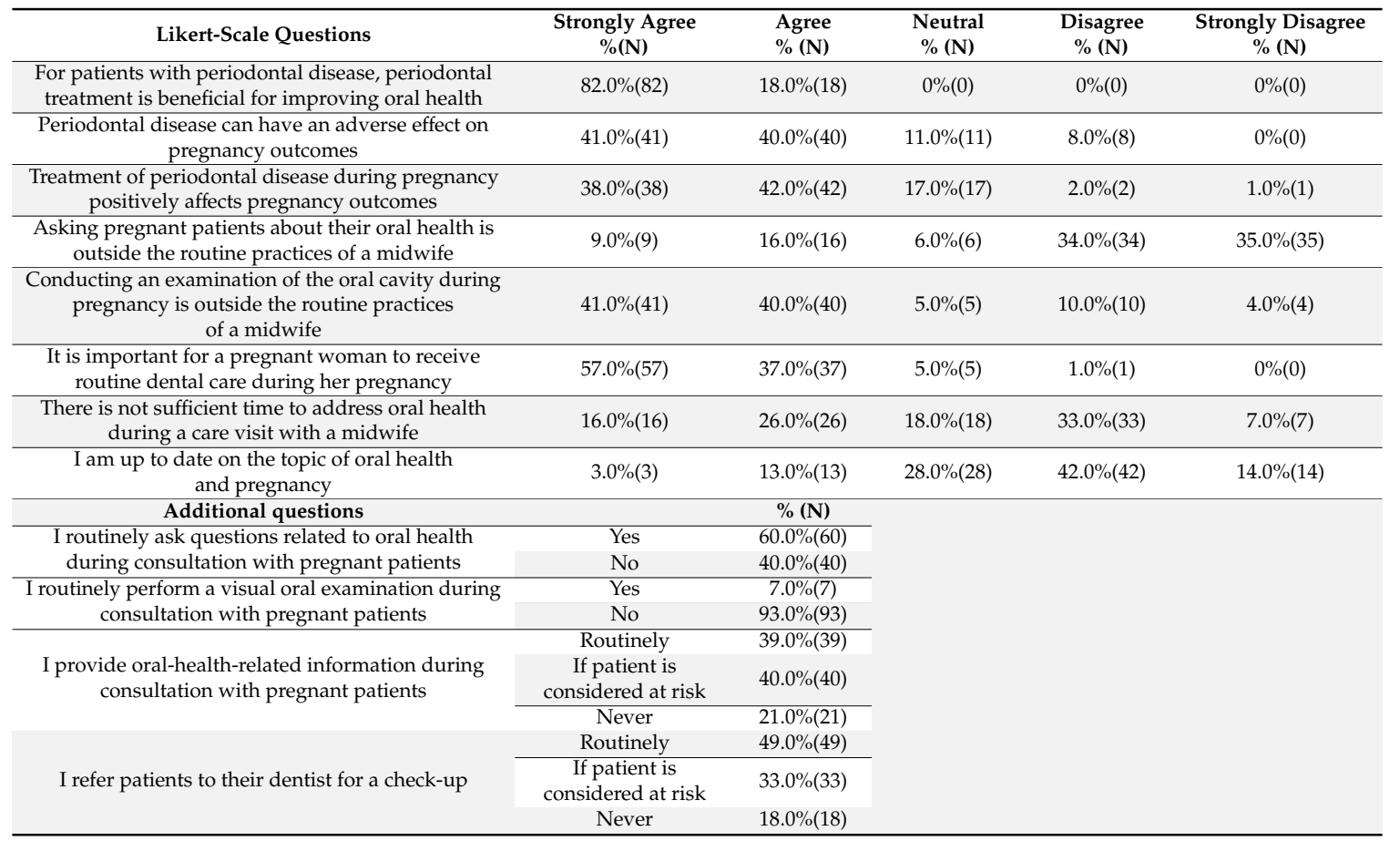

Knowledge and attitude scores were not significantly correlated with midwives' age, number of years of professional practice, nor frequency of dental visits $(p>0.05)$. There was a weak correlation between knowledge and attitude scores which was not statistically significant $(r=0.147, p=0.136)$.

\subsection{Attitudes and Practice Behaviour}

A higher attitude score significantly correlated with positive practice behaviour regarding antenatal oral health, such as providing oral-health-related information $(\mathrm{r}=0.403, \mathrm{p}<0.01)$ and routinely asking oral-health-related questions $(r=0.458, p<0.01)$. Specific attitudes that were significantly correlated with midwives providing oral-health-related information were that "Treating periodontal disease can positively affect pregnancy outcomes" $(\mathrm{p}=0.012)$, "An oral examination is within routine midwifery practice" $(p=0.018)$, "There is sufficient time to address oral health during an appointment" $(p<0.001)$, "Asking about oral health is within routine midwifery practice" $(\mathrm{p}<0.001)$, and "Routine dental care is important during pregnancy" $(\mathrm{p}=0.012)$. Attitudes that were significantly correlated with midwives referring patients for dental care included the beliefs that "Asking about oral health is within routine midwifery practice" $(p=0.027)$ and "Routine dental care is important during pregnancy" $(p=0.002)$.

\subsection{Midwives and Practice Location}

Knowledge and attitude scores correlated with practice location. Rural midwives had a significantly higher knowledge score $(\mathrm{r}=0.313, \mathrm{p}=0.001)$ and a higher attitude score $(\mathrm{r}=0.017$, $\mathrm{p}=0.865)$ than urban midwives. However, more urban midwives felt up to date on the topic of oral health and pregnancy $\left(X^{2}=16.56, \mathrm{df}=4, p=0.002\right)$ than rural midwives. More rural midwives felt that conducting an oral examination was within the routine scope of a midwife $\left(X^{2}=16.08, \mathrm{df}=4\right.$, $p=0.003)$, compared to urban midwives. There was no significant difference between urban and rural midwives regarding having insufficient time to address oral health during appointments. In terms of practice behaviour, significantly more rural midwives asked oral-health-related questions $\left(X^{2}=5.413\right.$, 
$\mathrm{df}=1, p=0.02)$, conducted an oral examination for pregnant patients $\left(X^{2}=9.884, \mathrm{df}=1, p=0.002\right)$, and provided oral-health-related information $\left(X^{2}=8.56, \mathrm{df}=2, p=0.014\right)$ than urban midwives.

\section{Discussion}

One of the objectives of the national law that governs the structure and regulation of many of the health professions in Australia is to ensure a dynamic workforce that is responsive to the needs of Australian society [61]. The role of midwives within the interdisciplinary healthcare team is one that is important to oral health; many patients who may not seek care from dental professionals will access care from midwives. It is therefore a missed opportunity if midwives are not suitably equipped with the knowledge and skills to deliver basic oral health promotion activities, provide oral health education, and act as advocates for oral healthcare and the access of services. By investigating midwives' knowledge, attitudes, and practice behaviour concerning the periodontal health of pregnant patients, this study represents the first step in identifying the gaps in current oral disease knowledge and building a stronger interdisciplinary health care team for improved patient outcomes.

All participants in this study were female and the average age was 43 years old. This is similar to the national demographics of Australian midwives, where average age was 44 years old and $99 \%$ of practicing midwives were female [62]. Most participants in this study trained as a midwife during or after the Australian antenatal care guidelines were updated to include oral health $-44.0 \%$ of participants practiced for less than 10 years as a midwife, while $32.0 \%$ of participants were current midwifery students [51].

Midwives in this study understood basic clinical signs of periodontal disease, but were unclear about the definition and aetiology of periodontal disease and the difference between periodontal disease and dental caries-two distinct oral diseases. For example, participants understood that periodontal disease is an inflammatory bacterial infection $(63.0 \%)$, but also incorrectly defined periodontal disease as a degenerative process (31.8\%). In addition, midwives correctly identified key clinical signs of periodontal disease such as gingival bleeding $(28.9 \%)$ and tooth mobility $(21.6 \%)$, but often misidentified dental caries $(16.0 \%)$ as a sign of periodontal disease. Midwives also incorrectly identified excessive sugar consumption $(14.7 \%)$ and tooth decay $(10.0 \%)$-both associated with dental caries-as aetiological factors for periodontal disease initiation more often than pregnancy $(8.6 \%)$ or genetics $(9.0 \%)$. While dental caries and periodontal disease are both important diseases that should be addressed during pregnancy, the aetiology and therefore the treatment methods for these two oral diseases are quite different. In terms of periodontal disease prevention, use of fluoridated toothpaste $(19.1 \%)$ was often incorrectly answered. Fluoridated toothpaste use is a preventative factor for dental caries, not periodontal disease. Control of psychological stress $(7.9 \%)$ was also rarely answered as a preventative measure for periodontal disease, although this is a factor midwives can help address during appointments. This underscores some misunderstanding amongst midwives regarding basic preventative measures and systemic inflammatory effects of periodontal disease. Similar results, including incorrectly believing periodontal disease development is associated with tooth decay and excessive sugar consumption, were also found in previous studies of maternal care providers $[27,28,30]$. This highlights gaps in basic oral health knowledge amongst Australian midwives, despite national regulation changes to include oral health in midwifery training [51].

Although Australian midwives agreed (91.1\%) that periodontal diseases influence pregnancy outcomes, there was also a lack of awareness regarding the consequences of antenatal periodontal disease on pregnancy outcomes. The most common responses for adverse pregnancy outcomes associated with periodontal disease were pre-term birth $(34.9 \%)$, low birthweight $(20.3 \%)$, and spontaneous abortion (17.7\%) - these were low percentages, considering all possible answers were correct and participants were allowed to choose more than one response.

This study found no correlation found between years of professional practice and knowledge, attitudes, and practice behaviour regarding antenatal oral health in spite of aforementioned national regulation changes [51]. Furthermore, the majority of participants $(76 \%)$ in this study had practiced 
for 10 years or less, and therefore should have been trained with the updated midwifery curricula. This suggests that Australian midwifery curricula have not been adequately adjusted to improve midwives' oral health knowledge. A previous study of Australian midwives in New South Wales found an association between oral health knowledge and years of experience, but only when midwives practiced for more than 20 years, suggesting this was likely not due to midwifery curricular changes mandated by Australian national guidelines [31].

Midwives' knowledge of antenatal oral health was only weakly correlated with their overall attitudes and practice behaviour $(\mathrm{p}>0.05)$. Most respondents $(81.0 \%)$ agreed that periodontal disease can have an adverse effect on pregnancy outcomes and most (80.0\%) agreed that treatment of periodontal disease during pregnancy positively affects pregnancy outcomes. This is similar to previous surveys on midwives regarding the importance of oral health during pregnancy [29-31,53]. However, only $39.0 \%$ of midwives routinely gave oral-health-related information to pregnant patients and less than half $(49.0 \%)$ routinely referred pregnant patients for dental care.

\subsection{Attitudes and Practice Behaviour}

Overall, positive attitudes amongst midwives towards oral health were strongly correlated with positive practice behaviour regarding antenatal oral health $(\mathrm{p}<0.01)$. In particular, the beliefs that "Asking about oral health is within routine midwifery practice" and that "Routine dental care is important during pregnancy" were strongly correlated with providing oral-health-related information during a consultation $(\mathrm{p}<0.001 ; \mathrm{p}=0.012$, respectively) and referring pregnant women to the dentist $(\mathrm{p}=0.027 ; \mathrm{p}=0.002$, respectively).

Only $24.2 \%$ of midwives in this study believed asking pregnant patients about their oral health is beyond the routine practices of a midwife. However, only $15.5 \%$ of midwives felt up to date on the topic of oral health and pregnancy. Similar views regarding antenatal oral health were found in surveys of Australian midwives practicing in urban Sydney and Victoria [31,63]. Surveys of midwives in Sydney, Australia and the USA also found approximately only $20 \%$ of midwives felt up to date regarding maternal oral health $[30,31]$.

$21.0 \%$ of midwives in this study never referred pregnant patients for a dental consult. Possible barriers to midwives addressing oral health during a routine visit include unclear referral pathways for dental care, the midwife's knowledge of oral health, and perceived lack of time during the appointment $[29,30]$. Previous research found that a major barrier to midwives addressing oral health during consultations was a lack of confidence to answer patient questions related to oral health [29]. Midwives in this study were also divided about whether there is time to address oral health during routine pregnancy consultation with patients. A total of $42.7 \%$ believed there is no time, while $39.8 \%$ believed there is time to address oral health. There was a strong positive correlation between midwives feeling they had sufficient time to address oral health and providing oral-health-related information $(p<0.001)$. Surveys on midwives in Melbourne, Australia found that having oral health information pamphlets available would reduce the amount of consultation time needed to address oral health, make midwives more likely to address oral health, and increased likelihood of patient referral to a dentist [29]. George et al. also found a positive correlation between midwives having information brochures regarding oral health and discussing the importance of oral health with pregnant patients [31].

\subsection{Differences in Practice Location}

Interestingly, rural midwives had a significantly better knowledge score $(p=0.001)$ regarding periodontal disease and pregnancy, and more positive attitudes and practice behaviours $(\mathrm{p}=0.014)$ regarding antenatal oral health than urban midwives. However, significantly more urban midwives felt they were up to date on the topic of antenatal oral health compared to rural midwives $(p=0.002)$. Significantly more rural midwives asked oral-health-related questions $(p=0.02)$, conducted an oral examination $(p=0.002)$, and provided oral-health-related information $(p=0.014)$ than urban midwives. Factors contributing to this disparity in knowledge, attitudes, and practice behaviour should be 
investigated in future research. Contributing factors may include educational training and opportunities available, patient case complexity, and work culture attitudes regarding interdisciplinary care.

\subsection{Limitations}

A weakness of this study was possible sample selection bias, as this was an online survey using social media to recruit participants. Participants were also not compensated and answered the survey during their spare time. Thus, study participants may be midwives who use social media more often and have more positive attitudes towards oral health. In this light, the results of this study may be more applicable towards midwives within this demographic. This study also did not include a question regarding participants' prior oral health knowledge from sources other than midwifery training, such as the pilot Midwifery Initiated Oral Health (MIOH) program [53]. However, the MIOH program is still in the early pilot stage and has trained a limited number of midwives in NSW and Victoria, therefore this was considered a negligible effect for this study [53].

\subsection{Future Directions}

Australian pilot initiatives have aimed to implement oral health curricula for midwives and midwifery students in Melbourne and Sydney [53]. However, recent studies found that Australian midwives still do not feel they have adequate knowledge about antenatal oral health and appropriate pathways to refer pregnant patients for dental care $[29,31,46]$. It remains yet to be seen whether these oral health education programs can be implemented nationally, and whether they will improve Australian midwives' knowledge of antenatal oral health and modify practice behaviours. Recent studies found that a major barrier to oral health care for pregnant patients was access to dental services and referral by midwives to a dentist [26,29,30]. Lim et al. found that although professional development courses regarding oral health were helpful for midwives to increase their knowledge and confidence, midwives forgot most information regarding oral health a few weeks after taking the course [29]. This implies that a clearer, more structured pathway of interprofessional communication, standardized information dissemination, and referral is needed between midwives and dentists regarding care of pregnant patients. Research has found information brochures regarding antenatal oral health were helpful for midwives to increase likelihood of addressing oral health [29,31].

The 2018 Australian Government Department of Health guidelines encourage inter-disciplinary collaboration for patient-centred care to improve patient outcomes [52]. Puertas et al. recommend that as part of general initial care, pregnant women should be informed that periodontal disease may increase their risk for adverse pregnancy outcomes [21]. They also recommend a brief oral health history to be gathered and a simple oral examination for pregnant women as part of initial general screening. Gaining awareness of midwives' perceptions regarding oral health is important for strengthening patient health care in a multidisciplinary teamwork setting. Management of antenatal oral diseases must move away from an isolated, singular approach tackled solely by dental professionals to a patient-centred interprofessional team approach for improved patient outcomes [41,42,64].

Future investigations of this topic may involve using a larger participant pool and including a survey question about participants' pre-existing knowledge and learning source regarding oral health. Further research may also investigate factors influencing the difference in knowledge and practice behaviour between urban and rural midwives, such as training opportunities available and work culture regarding interdisciplinary care. It would be helpful to assess whether the Australian guideline changes and consequent modifications to midwifery training lead to any improvement in patient-centred interprofessional health care and midwives' understanding of antenatal oral health.

\section{Conclusions}

Australian midwives have positive attitudes towards the importance of maternal oral health during pregnancy and believe that dental care can positively impact pregnancy outcomes. Viewing oral health as within routine midwifery practice was significantly associated with providing oral-health-related 
information and referring patients for dental care. Significantly more rural midwives provided oral-health-related information, asked oral-health-related questions, and conducted an oral examination for pregnant patients than urban midwives. Rural midwives also had significantly better knowledge of maternal gum disease than urban midwives. Overall, there are areas for improvement in midwives' understanding of the aetiology and prevention for gum disease during pregnancy. An improved understanding of maternal gum disease can give midwives a clearer understanding of how they can aid in improving pregnant women's oral health. The findings of this study show that further development of the Australian midwifery curricula is needed to support midwives in developing basic competencies to understand the fundamental signs and causes of oral disease, provide basic oral health information, and refer patients for further dental care. Midwives can play a key role in educating pregnant patients about oral health and connecting these patients at risk of gum disease with access to needed dental care. Interprofessional collaboration is critical for achieving optimal oral health and improving pregnancy outcomes.

Author Contributions: Conceptualization, J.G.-1.N. and A.C.L.H.; methodology, J.G.-I.N. and A.C.L.H.; software, J.G.-1.N. and S.N.; validation, J.G.-1.N., S.N. and A.C.L.H.; formal analysis, J.G.-I.N. and S.N.; investigation, J.G.-I.N.; resources, J.G.-I.N., S.N. and A.C.L.H.; data curation, J.G.-1.N. and S.N.; writing-original draft preparation, J.G.-1.N.; writing—review and edition, J.G.-I.N., S.N. and A.C.L.H.; visualization, J.G.-I.N.; supervision, A.C.L.H.; project administration, J.G.-1.N.; funding acquisition, J.G.-1.N. and A.C.L.H. All authors have read and agreed to the published version of the manuscript.

Funding: This research was funded by the Dental Student Research Trebitsch Grant from the Australian Dental Research Foundation.

Acknowledgments: Livia Ming-Wai Nguyen assisted with mapping geographical data using QGIS.

Conflicts of Interest: The authors declare no conflict of interest. The funders had no role in the design of the study; in the collection, analyses, or interpretation of data; in the writing of the manuscript, or in the decision to publish the results.

\section{Appendix A}

\section{Study Questionnaire}

Author's Note: Correct answers are bolded and italicized for questions where incorrect answers were provided. This formatting was removed before circulating the questionnaire to participants.

\section{Part 1:}

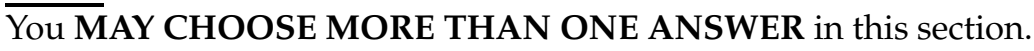

1. How would you classify periodontal diseases?
a. Auto-immune disorder
b. Inflammation and bacterial infection
c. Degenerative process
d. Osteoporosis
e. Metastatic process

2. Which clinical signs are associated with periodontal diseases?
a. Caries
b. Tooth mobility
c. Gingival bleeding
d. Alveolar bone destruction
e. Tooth loss

3. In your opinion, which risk factors contribute to gum disease initiation? (Choose maximum 4 answers)

a. Tooth decay 

b. Excessive sugar consumption
c. Genetics
d. Smoking
e. Dental plaque
f. Pregnancy
g. Poor oral hygiene

4. In your opinion, which risk factors contribute to gum disease progression? (Choose maximum 4 answers)
a. Tooth decay
b. Excessive sugar consumption
c. Genetics
d. Smoking
e. Dental plaque
f. Pregnancy
g. Poor oral hygiene

5. Which oral signs are often observed related to pregnancy?
a. Gingival overgrowth
b. Gingival bleeding
c. Caries
d. Tooth loss

6. Do periodontal diseases influence pregnancy outcomes?
a. No
b. Yes - Increased incidence of low genital-tract infection
c. Yes - Increased incidence of pre-eclampsia
d. Yes - Increased incidence of preterm birth
e. Yes - Increased incidence of low-weight newborn
f. Yes - Increased incidence of spontaneous abortion

7. Are periodontal diseases preventable during pregnancy?
a. No-They're an expected side effect during pregnancy.
b. Yes - They can be prevented or arrested during pregnancy.

8. Periodontal diseases can be prevented by:
a. Using fluoridated toothpaste
b. Using dental floss or interdental brushes
c. Effective tooth-brushing technique
d. Control of psychological stress
e. Smoking cessation

\section{Part 2:}

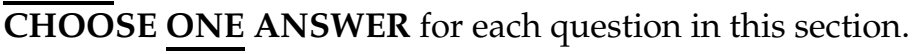

1. For patients with periodontal disease, periodontal treatment is beneficial for improving oral health.

a. Strongly agree, Agree, Neutral, Disagree, Strongly disagree

2. Periodontal disease can have an adverse effect on pregnancy outcomes. 
a. Strongly agree, Agree, Neutral, Disagree, Strongly disagree

3. Treatment of periodontal disease during pregnancy positively affects pregnancy outcomes.

a. Strongly agree, Agree, Neutral, Disagree, Strongly disagree

4. Asking pregnant patients about their oral health is outside the routine practices of a midwife.

a. Strongly agree, Agree, Neutral, Disagree, Strongly disagree

5. Conducting an examination of the oral cavity during pregnancy is outside the routine practices of a midwife

a. Strongly agree, Agree, Neutral, Disagree, Strongly disagree

6. It is important for a pregnant woman to receive routine dental care during her pregnancy.

a. Strongly agree, Agree, Neutral, Disagree, Strongly disagree

7. There is not sufficient time to address oral health during a care visit with a midwife.

a. Strongly agree, Agree, Neutral, Disagree, Strongly disagree

8. I am up to date on the topic of oral health and pregnancy.

a. Strongly agree, Agree, Neutral, Disagree, Strongly disagree

9. I routinely ask questions related to oral health during consultation with pregnant patients.

a. Yes, No

10. I routinely perform a visual oral examination during consultation with pregnant patients.

a. Yes, No

11. I provide oral health-related information during consultation with pregnant patients.
a. Routinely
b. If patient is considered at risk
c. Never

12. I refer patients to their dentist for a check-up.
a. Routinely
b. If patient is considered at risk
c. Never

\section{Part 3:}

1. Participant's Sex: Male, Female, Other

2. Participant's Age: (years)

3. How long have you practiced as a midwife?
a. Current Midwifery student
b. $\leq 10$ years
c. 10-20 years
d. 21-30 years
e. $\quad 31-40$ years
f. $40+$ years 
4. What is your current occupation?
a. Currently practicing in Australia
b. Retired midwife
c. Current midwifery student
d. Unemployed

5. Midwifery practice location: (Postal code)

6. Midwifery practice location:
a. Urban
b. Rural

7. Midwifery practice setting
a. Hospital
b. Private practice
c. Hospital and private practice

8. How would you rate your oral health?
a. Excellent
b. Good
c. Neutral
d. Poor
e. Very poor

9. On average, how often do you visit the dentist?
a. $\quad$ Every 6 months
b. Every 12 months
c. Every 12-18 months
d. Only if in pain
e. Never

10. Have you ever been diagnosed with periodontal disease? Yes/No

11. Have you ever been diagnosed with periodontal disease and received treatment for this condition? Yes/No 


\section{Appendix B}

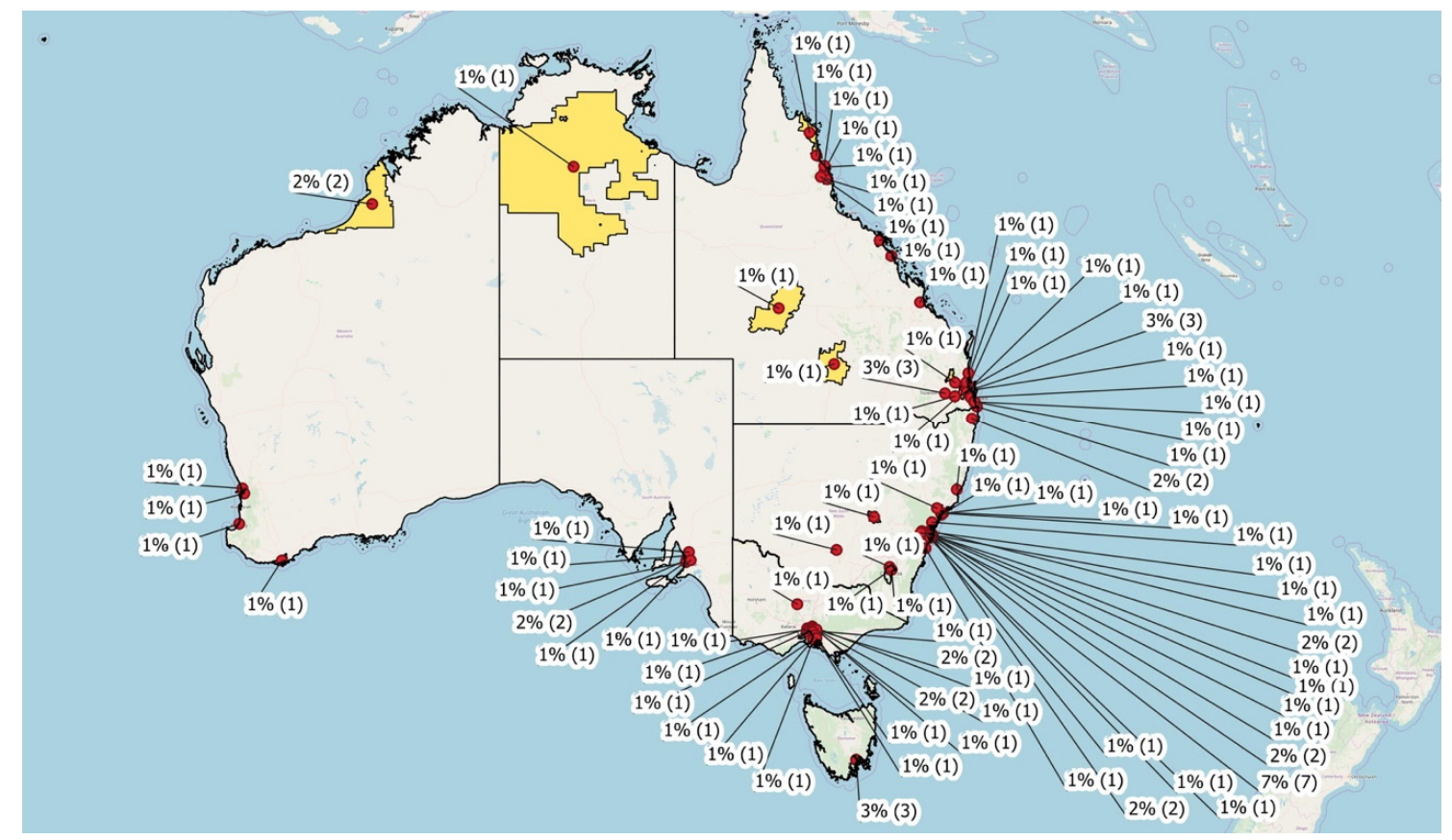

Figure A1. Geographical distribution of study respondents in Australia.

\section{References}

1. Zekeridou, A.; Mombelli, A.; Cancela, J.; Courvoisier, D.; Giannopoulou, C. Systemic inflammatory burden and local inflammation in periodontitis: What is the link between inflammatory biomarkers in serum and gingival crevicular fluid? Clin. Exp. Dent. Res. 2019, 5, 128-135. [CrossRef] [PubMed]

2. Borgnakke, W.S.; Ylöstalo, P.V.; Taylor, G.W.; Genco, R.J. Effect of periodontal disease on diabetes: Systematic review of epidemiologic observational evidence. J. Periodontol. 2013, 84, 135-152. [CrossRef] [PubMed]

3. Cardoso, E.M.; Reis, C.; Manzanares-Céspedes, M.C. Chronic periodontitis, inflammatory cytokines, and interrelationship with other chronic diseases. Postgrad. Med. 2018, 130, 98-104. [CrossRef] [PubMed]

4. Liccardo, D.; Cannavo, A.; Spagnuolo, G.; Ferrara, N.; Cittadini, A.; Rengo, C.; Rengo, G. Periodontal Disease: A Risk Factor for Diabetes and Cardiovascular Disease. IJMS 2019, 20, 1414. [CrossRef]

5. Kuo, L.-C.; Polson, A.M.; Kang, T. Associations between periodontal diseases and systemic diseases: A review of the inter-relationships and interactions with diabetes, respiratory diseases, cardiovascular diseases and osteoporosis. Public Health 2008, 122, 417-433. [CrossRef]

6. Winning, L.; Patterson, C.C.; Cullen, K.M.; Kee, F.; Linden, G.J. Chronic periodontitis and reduced respiratory function. J. Clin. Periodontol. 2019, 46, 266-275. [CrossRef]

7. Preventing Periodontal Disease; American Academy of Periodontology: Chicago, IL, USA, 2019; Available online: https://www.perio.org/consumer/prevent-gum-disease (accessed on 18 February 2020).

8. Wu, M.; Chen, S.-W.; Jiang, S.-Y. Relationship between Gingival Inflammation and Pregnancy. Mediat. Inflamm. 2015, 2015, 1-11. [CrossRef]

9. Silk, H.; Douglass, A.B.; Douglass, J.M.; Silk, L. Oral Health During Pregnancy. Am. Fam. Physician 2008, 77, 1139-1144.

10. Kruse, A.B.; Kuerschner, A.C.; Kunze, M.; Woelber, J.P.; Al-Ahmad, A.; Wittmer, A.; Vach, K.; Ratka-Krueger, P. Association between high risk for preterm birth and changes in gingiva parameters during pregnancy-A prospective cohort study. Clin. Oral Investig. 2018, 22, 1263-1271. [CrossRef]

11. Reyes, L.; Phillips, P.; Wolfe, B.; Golos, T.G.; Walkenhorst, M.; Progulske-Fox, A.; Brown, M. Porphyromonas gingivalis and adverse pregnancy outcome. J. Oral Microbiol. 2017, 9, 1374153. [CrossRef]

12. Dasanayake, A.P.; Gennaro, S.; Hendricks-Muñoz, K.D.; Chhun, N. Maternal Periodontal Disease, Pregnancy, and Neonatal Outcomes. MCN Am. J. Matern./Child Nurs. 2008, 33, 45-49. [CrossRef] [PubMed] 
13. Russell, S.L.; Mayberry, L.J. Pregnancy and Oral Health: A Review and Recommendations to Reduce Gaps in Practice and Research. MCN Am. J. Matern./Child Nurs. 2008, 33, 32-37. [CrossRef]

14. Morgan, M.A.; Crall, J.; Goldenberg, R.L.; Schulkin, J. Oral health during pregnancy. J. Matern.-Fetal Neonatal Med. 2009, 22, 733-739. [CrossRef] [PubMed]

15. Iheozor-Ejiofor, Z.; Middleton, P.; Esposito, M.; Glenny, A.-M. Treating periodontal disease for preventing adverse birth outcomes in pregnant women. Cochrane Database Syst. Rev. 2017. [CrossRef]

16. Vanterpool, S.F.; Been, J.V.; Houben, M.L.; Nikkels, P.G.J.; De Krijger, R.R.; Zimmermann, L.J.I.; Kramer, B.W.; Progulske-Fox, A.; Reyes, L. Porphyromonas gingivalis within Placental Villous Mesenchyme and Umbilical Cord Stroma Is Associated with Adverse Pregnancy Outcome. PLoS ONE 2016, 11, e0146157. [CrossRef] [PubMed]

17. Parthiban, P.S.; Mahendra, J.; Logaranjani, A.; Shanmugam, S.; Balakrishnan, A.; Junaid, M.; Namasivayam, A. Association between specific periodontal pathogens, Toll-like receptor-4, and nuclear factor- $\mathrm{kB}$ expression in placental tissues of pre-eclamptic women with periodontitis. J. Investig. Clin. Dent. 2018, 9, 1-8. [CrossRef] [PubMed]

18. Meqa, K.; Dragidella, F.; Disha, M.; Sllamniku-Dalipi, Z. The Association between Periodontal Disease and Preterm Low Birthweight in Kosovo. Acta Stomatol. Croat. 2017, 51, 33-40. [CrossRef] [PubMed]

19. Jaiman, G.; Nayak, P.A.; Sharma, S.; Nagpal, K. Maternal periodontal disease and preeclampsia in Jaipur population. J. Indian Soc. Periodontol. 2018, 22, 50-54.

20. Boggess, K.A. Maternal Oral Health in Pregnancy. Obstet. Gynecol. 2008, 111, 976-986. [CrossRef]

21. Puertas, A.; Magan-Fernandez, A.; Blanc, V.; Revelles, L.; O’Valle, F.; Pozo, E.; León, R.; Mesa, F. Association of periodontitis with preterm birth and low birth weight: A comprehensive review. J. Matern.-Fetal Neonatal Med. 2018, 31, 597-602. [CrossRef]

22. Codato, L.A.B.; Nakama, L.; Cordoni Júnior, L.; Higasi, M.S. Atenção odontológica à gestante: Papel dos profissionais de saúde. Ciênc. Saúde Coletiva 2011, 16, 2297-2301. [CrossRef] [PubMed]

23. Oral Health Care During Pregnancy Expert Workgroup. Oral Health Care During Pregnancy: A National Consensus Statement; National Maternal and Child Oral Health Resource Center: Washington, DC, USA, 2012.

24. Wilder, R.S. Is Dentistry at Risk? A Case for Interprofessional Education. J. Dent. Educ. 2008, 72, $1231-1237$. [PubMed]

25. Da Rocha, J.M.; Chaves, V.R.; Urbanetz, A.A.; Baldissera, R.D.S.; Rösing, C.K. Obstetricians' knowledge of periodontal disease as a potential risk factor for preterm delivery and low birth weight. Braz. Oral Res. 2011, 25, 248-254. [CrossRef] [PubMed]

26. Alves, R.T.; Ribeiro, R.A.; Costa, L.R.; Leles, C.R.; Freire, M.C.M.; Paiva, S.M. Oral Care during Pregnancy: Attitudes of Brazilian Public Health Professionals. Int. J. Environ. Res. Public Health 2012, 9, 3454-3464. [CrossRef]

27. Wilder, R.; Robinson, C.; Jared, H.L.; Boggess, K. Obstetricians' Knowledge and Practice Behaviors Concerning Periodontal Health and Preterm Delivery and Low Birth Weight. J. Dent. Hyg. 2007, 81, 1-15.

28. Cohen, L.; Schaeffer, M.; Davideau, J.-L.; Tenenbaum, H.; Huck, O. Obstetric Knowledge, Attitude, and Behavior Concerning Periodontal Diseases and Treatment Needs in Pregnancy: Influencing Factors in France. J. Periodontol. 2015, 86, 398-405. [CrossRef]

29. Lim, M.; Riggs, E.; Shankumar, R.; Marwaha, P.; Kilpatrick, N. Midwives' and women's views on accessing dental care during pregnancy: An Australian qualitative study. Aust. Dent. J. 2018, 63, 320-328. [CrossRef]

30. Wooten, K.T.; Lee, J.; Boggess, K.; Jared, H.; Wilder, R.S. Nurse Practitioner's and Certified Nurse Midwives' Knowledge, Opinions and Practice Behaviors regarding Periodontal Disease and Adverse Pregnancy Outcomes. J. Dent. Hyg. 2011, 85, 122-131.

31. George, A.; Dahlen, H.G.; Reath, J.; Ajwani, S.; Bhole, S.; Korda, A.; Chok, H.N.; Miranda, C.; Villarosa, A.; Johnson, M. What do antenatal care providers understand and do about oral health care during pregnancy: A cross-sectional survey in New South Wales, Australia. BMC Pregnancy Childbirth 2016, 16, 382. [CrossRef]

32. De Oliveira Diniz, L.V.; da Costa, C.H.M.; Oliveira, A.F.B.; Forte, F.D.S. Health professionals' knowledge of oral health preventive practices regarding early childhood health care. J. Public Health 2012, 20, 513-518. [CrossRef]

33. George, A.; Johnson, M.; Duff, M.; Ajwani, S.; Bhole, S.; Blinkhorn, A.; Ellis, S. Midwives and oral health care during pregnancy: Perceptions of pregnant women in south-western Sydney, Australia: Oral health care during pregnancy. J. Clin. Nurs. 2012, 21, 1087-1096. [CrossRef] [PubMed] 
34. Strafford, K.E.; Shellhaas, C.; Hade, E.M. Provider and patient perceptions about dental care during pregnancy. J. Matern.-Fetal Neonatal Med. 2008, 21, 63-71. [CrossRef] [PubMed]

35. George, A.; Ajwani, S.; Bhole, S.; Dahlen, H.; Reath, J.; Korda, A.; Ng Chok, H.; Miranda, C.; Villarosa, A.; Johnson, M. Knowledge, attitude and practises of dentists towards oral health care during pregnancy: A cross sectional survey in New South Wales, Australia. Aust. Dent. J. 2017, 62, 301-310. [CrossRef] [PubMed]

36. George, A.; Ajwani, S.; Johnson, M.; Dahlen, H.; Blinkhorn, A.; Bhole, S.; Ellis, S.; Zheng, C.; Dawes, W. Developing and Testing of an Oral Health Screening Tool for Midwives to Assess Pregnant Woman. Health Care Women Int. 2015, 36, 1160-1174. [CrossRef]

37. Bhole, S.; Ajwani, S.; George, A.; Johnson, M.; Blinkhorn, A.; Ellis, S. Oral health care model for pregnant women in Southwest Sydney. In Proceedings of the 88th International Association of Dental Research General Session, Barcelona, Spain, 14-17 July 2010. Journal of Dental Research: Volume 89, Abstract no. 138958.

38. George, A.; Johnson, M.; Blinkhorn, A.; Ajwani, S.; Ellis, S.; Bhole, S. Views of pregnant women in South Western Sydney towards dental care and an oral-health program initiated by midwives. Health Promot. J. Aust. 2013, 24, 178-184. [CrossRef]

39. Keirse, M.J.N.C.; Plutzer, K. Women's attitudes to and perceptions of oral health and dental care during pregnancy. J. Perinatal Med. 2010, 38. [CrossRef]

40. George, A.; Lang, G.; Johnson, M.; Ridge, A.; de Silva, A.M.; Ajwani, S.; Bhole, S.; Blinkhorn, A.; Dahlen, H.G.; Ellis, S.; et al. The evaluation of an oral health education program for midwives in Australia. Women Birth 2016, 29, 208-213. [CrossRef]

41. Batchelor, P. Is periodontal disease a public health problem? Br. Dent. J. 2014, 217, 405-409. [CrossRef]

42. Kaufman, L.B.; Henshaw, M.M.; Brown, B.P.; Calabrese, J.M. Oral Health and Interprofessional Collaborative Practice. Dent. Clin. N. Am. 2016, 60, 879-890. [CrossRef]

43. Mortensen, B.; Lieng, M.; Diep, L.M.; Lukasse, M.; Atieh, K.; Fosse, E. Improving Maternal and Neonatal Health by a Midwife-led Continuity Model of Care-An Observational Study in One Governmental Hospital in Palestine. EClinicalMedicine 2019, 10, 84-91. [CrossRef]

44. Sandall, J.; Soltani, H.; Gates, S.; Shennan, A.; Devane, D. Midwife-led continuity models versus other models of care for childbearing women. Cochrane Database Syst. Rev. 2016. [CrossRef] [PubMed]

45. Homer, C.S. Models of maternity care: Evidence for midwifery continuity of care. Med. J. Aust. 2016, 205, 370-374. [CrossRef] [PubMed]

46. Dahlen, H.G.; Johnson, M.; Hoolsema, J.; Norrie, T.P.; Ajwani, S.; Blinkhorn, A.; Bhole, S.; Ellis, S.; Srinivas, R.; Yaacoub, A.; et al. Process evaluation of the midwifery initiated oral health-dental service program: Perceptions of midwives in Greater Western Sydney, Australia. Women Birth 2019, 32, 159-165. [CrossRef] [PubMed]

47. George, A.; Villarosa, A.; Patterson Norrie, T.; Hoolsema, J.; Dahlen, H.; Ajwani, S.; Bhole, S.; Blinkhorn, A.; Srinivas, R.; Yaacoub, A.; et al. Process evaluation of the midwifery initiated oral health-dental service program: Perceptions of pregnant women. Aust. Dent. J. 2019, 64, 55-65. [CrossRef] [PubMed]

48. National Maternal and Child Oral Health Resource Center. Oral Health Care During Pregnancy: A Resource Guide, 2nd ed.; National Maternal and Child Oral Health Resource Center: Washington, DC, USA, 2017.

49. Sanz, M.; Kornman, K. Periodontitis and adverse pregnancy outcomes: Consensus report of the Joint EFP/AAP Workshop on Periodontitis and Systemic Diseases. J. Clin. Periodontol. 2013, 40, 164-169. [CrossRef] [PubMed]

50. NHS Inform. Looking After Your Teeth and Gums in Pregnancy; NHS Health Scotland: Edinburgh, Scotland, 2019; Available online: https://www.nhsinform.scot/ready-steady-baby/pregnancy/looking-after-yourselfand-your-baby/looking-after-your-teeth-and-gums-in-pregnancy (accessed on 18 February 2020).

51. Australian Health Ministers' Advisory Council. Clinical Practice Guidelines: Antenatal Care-Module 1; Australian Government Department of Health and Ageing: Canberra, ACT, Australia, 2012.

52. Australian Government Department of Health. Clinical Practice Guidelines: Pregnancy Care; Australian Government Department of Health: Canberra, ACT, Australia, 2018.

53. Duff, M.; Dahlen, H.G.; Burns, E.; Priddis, H.; Schmied, V.; George, A. Designing an oral health module for the Bachelor of Midwifery program at an Australian University. Nurse Educ. Pr. 2017, 23, 76-81. [CrossRef]

54. Midwife Accreditation Standards 2014; Australian Nursing and Midwifery Accreditation Council: Canberra, ACT, Australia, 2014; ISBN 978-0-9808210-6-2. Available online: https:/www.anmac.org.au/sites/default/ files/documents/ANMAC_Midwife_Accreditation_Standards_2014.pdf (accessed on 20 May 2019). 
55. Nursing and Midwifery Board of Australia. Midwife Standards for Practice; Nursing and Midwifery Board AHPRA: Canberra, ACT, Australia, 2018. Available online: https://www.nursingmidwiferyboard.gov.au/ Codes-Guidelines-Statements/Professional-standards/Midwife-standards-for-practice.aspx (accessed on 20 May 2019).

56. Internet, Phone, Mail, and Mixed-Mode Surveys: The Tailored Design Method, 4th ed.; Dillman, D.A.; Smyth, J.D.; Christian, L.M. (Eds.) Wiley: Hoboken, NJ, USA, 2014; ISBN 978-1-118-45614-9.

57. Peterson, R. Constructing Effective Questionnaires; SAGE Publications, Inc.: Thousand Oaks, CA, USA, 2000; ISBN 978-0-7619-1641-3.

58. Handbook of Health Research Methods: Investigation, Measurement and Analysis; Bowling, A. (Ed.) Reprinted; Open Univ. Press: Maidenhead, UK, 2009; ISBN 978-0-335-21460-0.

59. Harris, P.A.; Taylor, R.; Thielke, R.; Payne, J.; Gonzalez, N.; Conde, J.G. Research electronic data capture (REDCap) - A metadata-driven methodology and workflow process for providing translational research informatics support. J. Biomed. Inform. 2009, 42, 377-381. [CrossRef]

60. Harris, P.A.; Taylor, R.; Minor, B.L.; Elliott, V.; Fernandez, M.; O’Neal, L.; McLeod, L.; Delacqua, G.; Delacqua, F.; Kirby, J.; et al. The REDCap consortium: Building an international community of software platform partners. J. Biomed. Inform. 2019, 95, 103208. [CrossRef]

61. Health Practitioner Regulation National Law 2018 (ACT), Republication No 9; ACT Parliamentary Counsel: Canberra, ACT, Australia, 2019. Available online: http://www.legislation.act.gov.au/a/db_39269/current/pdf/ db_39269.pdf (accessed on 21 May 2019).

62. Australian Institute of Health and Welfare. Nursing and Midwifery Workforce 2015; Australian Institute of Health and Welfare: Canberra, ACT, Australia, 2016.

63. Heilbrunn-Lang, A.Y.; de Silva, A.M.; Lang, G.; George, A.; Ridge, A.; Johnson, M.; Bhole, S.; Gilmour, C. Midwives' perspectives of their ability to promote the oral health of pregnant women in Victoria, Australia. BMC Pregnancy Childbirth 2015, 15, 110. [CrossRef]

64. Catford, J. Turn, turn, turn: Time to reorient health services. Health Promot. Int. 2014, 29, 1-4. [CrossRef]

(C) 2020 by the authors. Licensee MDPI, Basel, Switzerland. This article is an open access article distributed under the terms and conditions of the Creative Commons Attribution (CC BY) license (http://creativecommons.org/licenses/by/4.0/). 